\title{
The role of genetics in stroke
}

\author{
John Francis, Senthil Raghunathan, Pradeep Khanna
}

Postgrad Med J 2007;83:590-595. doi: 10.1136/pgmj.2007.060319

Stroke is a leading cause of death and disability in developed countries. While both modifiable and non-modifiable risk factors are acknowledged, studies have shown that these may account for just $50 \%$ of stroke risk and that other factors, including genetic ones, may be important. Over recent years family history, twin and candidate gene studies have supported this and various mendelian stroke syndromes have now been identified in humans. This article provides an up-to-date summary of the common single gene disorders associated with stroke as a principle manifestation, including their genetic basis, pathogenesis, presentation and suggested management. Often these disorders present with stroke at a young age; this article provides a practical approach to the management and investigation of a young stroke patient.

See end of article for authors' affiliations

.......

Correspondence to: John Francis, Nevill Hall Hospital, Brecon Road, Abergavenny, NP7 7É, UK; FrancisJA@@Cardiff.ac. uk

Received 29 March 2007 Accepted 22 May 2007
S roke is defined as a focal (or at times global) neurological impairment of sudden onset, lasting more than $24 \mathrm{~h}$ (or leading to death) and of presumed vascular origin. ${ }^{1}$ Stroke is the third most common cause of death and the most common cause of disability in developed countries; $85 \%$ are due to cerebral ischaemia and $15 \%$ are due to primary intracerebral haemorrhage. ${ }^{2}$ Non- $^{3}$ modifiable risk factors include age, race and male sex, and acquired risk factors include cigarette smoking, hypertension, diabetes and obesity. However, in 1989, after a prospective study of 1805 stroke patients, Sacco and colleagues concluded that these risk factors account for approximately $50 \%$ of stroke risk; this infers that other influences, including genetic ones, may be involved in stroke risk. ${ }^{4}$ With its heterogeneous aetiopathogenesis the exact role of genetics in causing stroke remains controversial; family history studies, ${ }^{5}$ twin studies ${ }^{6}$ and studies adopting candidate gene approaches ${ }^{7}$ have produced diverse results. ${ }^{8}$ Nonetheless, there is a definite suggestion that susceptibility to stroke is influenced by genetic factors and various mendelian stroke syndromes have been identified in humans. ${ }^{9}$ Genetic predisposition to stroke can be categorised as either a single gene disorder or as a polygenic disorder. Many studies investigating potential risk genes for stroke exist but the major advances in our understanding of these conditions have been on single gene disorders; it is on these that this article will focus. Table 1 provides a summary of the single gene disorders associated with stroke covered in this article. ${ }^{8} 10$
SINGLE GENE DISORDERS AND STROKE Cerebral autosomal dominant arteriopathy with subcortical infarcts and leucoencephalopathy (CADASIL) Genetic basis

The human NOTCH3 gene on chromosome 19p13.1-13.2 encodes the human Notch3 receptor, a 2321 amino acid type I transmembrane protein that forms part of the notch intercellular communication system. This system is thought to be involved in controlling cell fate during development and has important roles in arterial development with the Notch3 receptor being expressed on vascular smooth muscle cells. Cerebral autosomal dominant arteriopathy with subcortical infarcts and leucoencephalopathy (CADASIL) is caused by mutations of the human NOTCH3 gene; the majority are missense mutations involving cysteine residues, $90 \%$ of which involve exons $2-6 .{ }^{11}{ }^{12}$

\section{Pathogenesis}

Methods by which NOTCH3 gene mutations become pathogenic are poorly understood, with Peters et al demonstrating that the majority of mutations do not affect Notch3 receptor signalling. ${ }^{13}$ However, investigation of brain tissue of CADASIL patients obtained at autopsy or during surgery (compared with normal controls) showed that the extracellular domains of mutant Notch3 receptors accumulate at the cytoplasmic membrane of vascular smooth muscle cells, in close vicinity to but not within the granular osmiophilic material. Immuno-electron microscopy identifies a non-atherosclerotic and non-amyloid vasculopathy. ${ }^{14}$

\section{Clinical manifestations}

Approximately $70 \%$ of patients present with recurrent ischaemic episodes (stroke or transient ischaemic attacks (TIA)) between 30 and 60 years of age (average age approximately 46 years); at presentation nearly $50 \%$ will have cognitive defects. Other associated symptoms include psychiatric disturbances, pseudobulbar palsy and migraine with or without aura. ${ }^{15}$ Other tissues including skin and muscle vasculature ${ }^{16}$ and

Abbreviations: CADASIL, cerebral autosomal dominant arteriopathy with subcortical infarcts and leucoencephalopathy; CARASIL, cerebral autosomal recessive arteriopathy with subcortical infarcts and leucoencephalopathy; CBS, cystathione $\beta$-synthase; $\mathrm{HbF}$, fetal haemoglobin; HbS, haemoglobin S; HERNS, hereditary endotheliopathy, retinopathy, nephropathy and strokes; MELAS, mitochondrial myopathy, encephalopathy, lactacidosis and stroke; MMD, moya-moya disease; MRI, magnetic resonance imaging; NF1, neurofibromatosis type 1; SAH, subarachnoid haemorrhage; TIA, transient ischaemic attack 
Table 1 Single gene disorders associated with stroke

\begin{tabular}{|c|c|c|c|c|}
\hline Disorder (inheritance) & Chromosome & Protein & Stroke mechanism & Age of disease presentation \\
\hline CADASIL (autosomal dominant) & $19 p 13.1-13.2$ & Notch3 receptor & Small vessel disease & $30-60$ years \\
\hline CARASIL (autosomal recessive) & $19 \mathrm{p} 13.1-13.2$ & Notch3 receptor & Small vessel disease & $25-35$ years \\
\hline $\begin{array}{l}\text { Moya-moya disease (autosomal } \\
\text { dominant) }\end{array}$ & $\begin{array}{l}3 p 24.2-p 26 \text { and } \\
\text { others }\end{array}$ & Numerous & $\begin{array}{l}\text { Internal carotid stenosis with new vessel } \\
\text { formation }\end{array}$ & $\begin{array}{l}<5 \text { years (juvenile) } \\
30-50 \text { years (adult) }\end{array}$ \\
\hline Fabry disease (X-linked recessive) & $\mathrm{Xq} 22$ & $\alpha$-galactosidase $\mathrm{A}$ & Large and small vessel disease & $<40$ years \\
\hline $\begin{array}{l}\text { Sickle-cell anaemia (autosomal } \\
\text { recessive) }\end{array}$ & $11 \mathrm{p} 15.4$ & $\beta$-haemoglobin & $\begin{array}{l}\text { Large and small vessel disease, } \\
\text { haemodynamic insufficiency }\end{array}$ & Childhood \\
\hline $\begin{array}{l}\text { Homocystinuria (autosomal } \\
\text { recessive) }\end{array}$ & $21 \mathrm{q} 22.3$ and others & $\begin{array}{l}\text { Cystathione } \beta \text {-synthase } \\
\text { and others }\end{array}$ & $\begin{array}{l}\text { Large and small vessel disease, } \\
\text { cardioembolism, arterial dissection }\end{array}$ & Childhood \\
\hline MELAS (maternal) & Mitochondrial & Transfer RNA & Complex & Variable \\
\hline $\begin{array}{l}\text { Marfan syndrome (autosomal } \\
\text { dominant) }\end{array}$ & $15 q 21.1$ & Fibrillin 1 & Cardioembolism and arterial dissection & Childhood \\
\hline $\begin{array}{l}\text { Ehlers-Danlos syndrome } \\
\text { (autosomal dominant) }\end{array}$ & $2 q 31$ & Collagen type III & Arterial dissection & Childhood \\
\hline
\end{tabular}

CADASIL, cerebral autosomal dominant arteriopathy with subcortical infarcts and leucoencephalopathy; CARASIL, cerebral autosomal recessive arteriopathy with subcortical infarcts and leucoencephalopathy; MELAS, mitochondrial myopathy, encephalopathy, lactacidosis and stroke; RNA, ribonucleic acid.

peripheral nerves, ${ }^{17}$ and organs including the heart and liver may be involved. ${ }^{18}$

\section{Diagnosis and management}

Magnetic resonance imaging (MRI) shows numerous focal lacunar infarcts and diffuse subcortical T2-weighted hyperintensity (fig 1). However, similar changes are observed in patients with cardiovascular risk factors and may just indicate small vessel disease. A characteristic radiological marker of CADASIL is bilateral temporal pole hyperintensity. The external capsule and corpus callosum are also frequently involved and may help to distinguish the disease. ${ }^{19}$ Another characteristic finding is the deposition of smudged periodic acid-Schiffpositive granules known as granular osmiophilic materials in the media of small arteries and arterioles. The medial smooth muscle cells are completely lost, and intense adventitial fibrosis is present. ${ }^{20}$ Molecular genetic analysis of the Notch3 gene is the definitive diagnostic test. CADASIL patients are provided with counselling, support and symptomatic control; no specific treatment currently exists. Average survival is 65-70 years of age with approximately $40 \%$ of patients dying from pneumonia. ${ }^{21}$

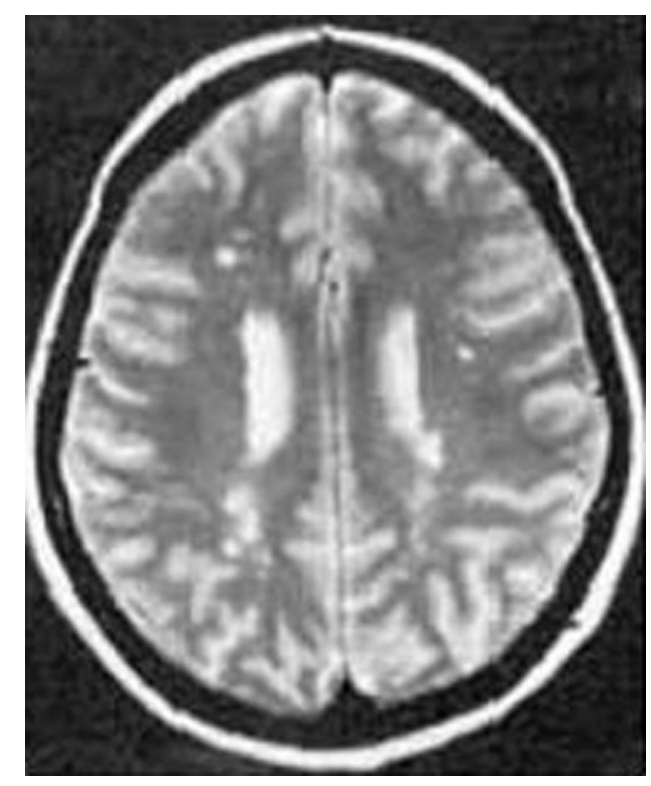

Figure 1 T2-weighted magnetic resonance images showing hyperintense lesions affecting the subcortical white matter in cerebral autosomal dominant arteriopathy with subcortical infarcts and leucoencephalopathy (CADASIL). www.neurocast.com (accessed 20 March 2007).

\section{Cerebral autosomal recessive arteriopathy with subcortical infarcts and leucoencephalopathy (CARASIL) (Maeda syndrome)}

Cerebral autosomal recessive arteriopathy with subcortical infarcts and leucoencephalopathy (CARASIL) was first identified in Japan in 1995. A review of 17 patients with young-adultonset atherosclerotic leucoencephalopathy, alopecia and lumbago revealed a CADASIL related disorder transmitted in an autosomal recessive manner. The age of onset ranged from 2530 years and common clinical features were acute lumbago, spondylosis deformans, diffuse baldness, and progressive motor and mental deterioration. ${ }^{22}$ Subsequent comparisons of these two conditions revealed that, despite their similarities (familiarity, encephalopathy of Binswanger type and absence of vascular risk factors), important differences exist between CADASIL and CARASIL (table 2). ${ }^{23}$

\section{Moya-moya disease (MMD) \\ Genetic basis}

Moya-moya disease (MMD) is predominantly found in East Asian populations, with most reported cases originating from Japan, Korea and China. Although the exact aetiology is unknown, this geographical pattern, together with a general female predominance and familial pattern observed in approximately $12 \%$ of cases, suggest a genetic influence. Furthermore, non-parametric linkage analyses have identified linkages to chromosomes 3p24.2-p26, 6q25, 8q23, 12p12 and 17q25. The proposed pattern of inheritance is autosomal dominant with incomplete penetrance. ${ }^{24}$

Table 2 A comparison of CADASIL and CARASIL

\begin{tabular}{lll}
\hline Comparison & CADASIL & CARASIL \\
\hline $\begin{array}{l}\text { Mean age of } \\
\text { encephalopathy }\end{array}$ & 45 years & 32 years \\
$\begin{array}{l}\text { Male to female ratio } \\
\text { Prevalence of stroke }\end{array}$ & $2: 1$ & Approximately 100\% \\
$\begin{array}{l}\text { Psychiatric features } \\
\text { Severe mood disorders }\end{array}$ & $\begin{array}{l}\text { Approximately 2/3 } \\
\text { Euphoria, emotional } \\
\text { lability }\end{array}$ \\
$\begin{array}{l}\text { Presence of migraine } \\
\text { White matter lesions } \\
\text { on MRI }\end{array}$ & $\begin{array}{l}\text { Yes } \\
\text { Punctuated and nodular }\end{array}$ & $\begin{array}{l}\text { No } \\
\text { Diffuse and } \\
\text { homogenous }\end{array}$ \\
\hline
\end{tabular}

CADASIL, cerebral autosomal dominant arteriopathy with subcortical infarcts and leucoencephalopathy; CARASIL, cerebral autosomal recessive arteriopathy with subcortical infarcts and leucoencephalopathy; MRI, magnetic resonance imaging. 


\section{Pathogenesis}

MMD is characterised by intimal thickening in the walls of the terminal portions of the internal carotid vessels, usually bilaterally; the cerebral vessels originating from the circle of Willis may also be involved. An abnormal vascular network forms in the base of the brain due to new vessel formation around the circle of Willis (perforators and anastomotic vessels). With cerebral angiography these new vessels appear as a puff of smoke, giving the name moya-moya (Japanese for puff of smoke) (www.emedicine.com, accessed 20 March 2007). (fig 2).

\section{Clinical manifestations}

MMD has two peak ages of onset, initially at 5 years of age (juvenile type), and subsequently at 30-50 years of age (adult type). In juvenile type MMD cerebral ischaemia due to vascular stenosis usually causes symptoms, whereas in adult type, although ischaemia is recognised, presentation is normally with intracerebral haemorrhages due to rupture of fragile collateral vessels formed at a younger age. ${ }^{25}$ Examination findings depend on the location and severity of the ischaemic insult or haemorrhage and may include hemiparesis, sensory symptoms, and movement disorders.

\section{Diagnosis and management}

Diagnosis is largely dependent on imaging with MRI and cerebral angiography; diagnoses can be made in asymptomatic patients. Juvenile MMD may benefit from antiplatelet agents and anticoagulants whereas both of these must be avoided with adult type. Direct, indirect and combined surgical bypass operations are further management options. ${ }^{25}$ Prognosis varies greatly and depends on the severity and progression of the disorder.

\section{Fabry disease \\ Genetic basis}

Fabry disease is the second most common glycosphingolipid storage disorder (after Gaucher disease). It is an X-linked lysosomal storage disease resulting in a deficiency of the lysosomal hydrolase, $\alpha$-galactosidase A (chromosome Xq22). ${ }^{26}$

\section{Pathogenesis}

Deficiency of $\alpha$-galactosidase A results in uncleaved glycosphingolipids (predominantly globotriosylceramide (Gb3)) accumulating in the lysosomes of various cells, including the vascular endothelium. This accumulation causes cellular dysfunction, eventually leading to organ failure. ${ }^{26}$

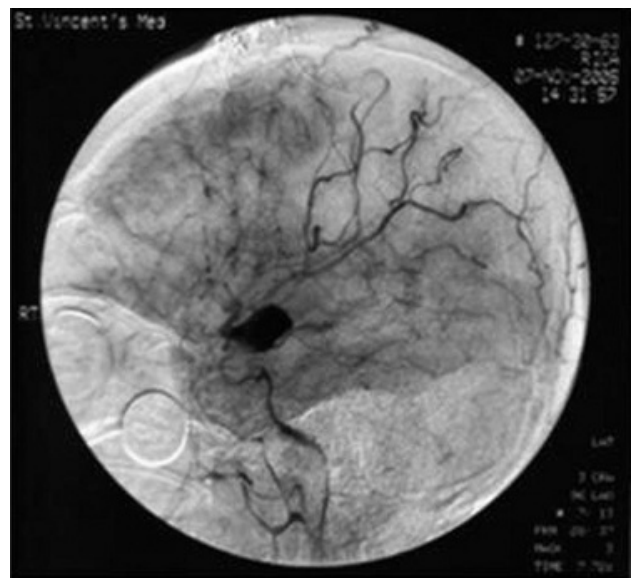

Figure 2 Magnetic resonance angiogram showing characteristic "puff" of moya-moya disease. www.ispub.com (accessed 20 March 2007).

\section{Clinical manifestations}

The classical symptom of Fabry disease is neuropathic pain due to lipid accumulation in sensory nerve pathways. Deposits may also be present in renal tubules and glomeruli, cardiac muscle and conducting fibres, and in specific cortical and brain stem structures. Major clinical manifestations thus include renal failure, cardiomyopathy and multiple strokes. ${ }^{26}$ Stroke occurs in approximately $25 \%$ of patients, often before the age of 40 years, with equal frequency in carotid and vertebrobasilar distributions. Stroke may be as a direct result of small vessel occlusion by lipid deposition, but can also be a manifestation of large vessel disease, or due to embolism from associated cardiac disease. $^{27}$

\section{Diagnosis and management}

Other than clinical presentation, the diagnosis is confirmed by measuring a reduced $\alpha$-galactosidase A activity and by genetic analysis. Enzyme replacement with recombinant $\alpha$-galactosidase A has shown promising results, reversing abnormal cerebrovascular responses in Fabry disease patients. ${ }^{28}$ The median cumulative survival time in a study of 51 patients was 50 years, with causes of death often being multiple, but predominantly involving renal failure and stroke. ${ }^{26}$

\section{Sickle cell anaemia \\ Genetic basis}

Sickle cell anaemia is an autosomal recessive disease resulting from the substitution of valine for glutamate in the $\beta$-chain of haemoglobin that produces the defective protein, haemoglobin $\mathrm{S}(\mathrm{HbS})$. Patients can be either homozygous or heterozygous for the condition; heterozygotes exhibit a disease trait and generally only show symptoms under stressful conditions (for example, severe hypoxia) (www.emedicine.com).

\section{Pathogenesis}

Adjacent HbS molecules interact through hydrophobic bonds causing them to polymerise, forming large aggregates that distort the red blood cell into a "sickle" shape. These abnormal cells cause blood vessel obstruction leading to tissue hypoxia, promoting further red blood cell "sickling". Patients can develop MMD-like changes around the circle of Willis (www.emedicine.com).

\section{Clinical manifestations}

Clinical presentation can be diverse with any organ system being susceptible. Classical manifestations are divided into vaso-occlusive crises (organ ischaemia due to vessel occlusion; cause of strokes), haematological crises (sudden exacerbation of anaemia; cause of strokes), and infectious crises (defective immunity due to dysfunctional spleen). Sickle cell anaemia is the most common cause of stroke in children; clinically apparent strokes are often due to vasculopathy of the distal internal carotid arteries and proximal middle cerebral arteries. Silent strokes are also frequent. ${ }^{29}$ Eleven per cent of patients with sickle cell anaemia suffer a clinically apparent stroke by 20 years and $24 \%$ by 45 years of age. The greatest risk of stroke is during the first decade of life; this reduces up until 29 years of age before another smaller peak of incidence. Haemorrhagic strokes are most common during the third decade of life. ${ }^{30}$ Stroke recurrence is reported in up to two-thirds of patients, usually occurring within 3 years of the initial event. ${ }^{29}$

\section{Diagnosis and management}

Diagnosis is largely clinical with confirmation from haemoglobin electrophoresis. Transcranial ultrasound is a useful screening tool to identify children at high risk of stroke with significantly narrowed vessels. Repeat blood transfusions improve oxygen saturations and reduce red blood cell sickling, 
potentially preventing strokes. ${ }^{31}$ Hydroxyurea increases fetal haemoglobin ( $\mathrm{HbF}$ ) which inhibits $\mathrm{HbS}$ polymerisation, thus reducing the risk of stroke. It is a possible alternative to transfusion therapy. ${ }^{32}$ Bone marrow transplantation offers the only potential cure for sickle cell anaemia.

\section{Homocystinuria \\ Genetic basis}

Homocystinuria describes a group of inherited conditions where methionine metabolism is defective. Most are inherited as an autosomal recessive disease and most are due to a deficiency of the enzyme cystathione $\beta$-synthase (CBS) that converts homocysteine to cystathione; plasma homocysteine concentrations rise $(>100 \mu \mathrm{mol} / \mathrm{l})$, as do urinary concentrations. ${ }^{33}$ In 1988 Munke and colleagues mapped the CBS gene to chromosome 21q22.3, since when several mutations have been identified. ${ }^{34}$

\section{Pathogenesis}

The mechanism by which elevated homocysteine concentrations result in clinical manifestations remains unclear, although in vitro it has been shown to cause endothelial dysfunction and promote smooth muscle cell proliferation. ${ }^{35}$ Reports have shown that homocysteinuria can cause stroke through atherosclerosis, thromboembolism, small vessel disease and arterial dissection. ${ }^{10}$

\section{Clinical manifestations}

Homocystinuria causes a multisystemic disorder. The full phenotype consists of mental retardation, ectopia lentis, skeletal deformities and thromboembolic events. An international study identified that approximately $50 \%$ of patients with inherited CBS deficiency suffered a thromboembolic event by 29 years of age; $32 \%$ of these were stroke. ${ }^{35}$

\section{Diagnosis and management}

Diagnosis is through the clinical picture and urine amino acid analysis and elevated plasma methionine. Patients must adhere to a methionine-restricted diet. Approximately 50\% of patients respond to pyridoxine; those who do generally suffer with a milder phenotype with a later onset of symptoms. ${ }^{36}$

\section{Mitochondrial myopathy, encephalopathy, lactacidosis and stroke (MELAS)}

Genetic basis

Mitochondrial myopathy, encephalopathy, lactacidosis and stroke (MELAS) is a progressive neurodegenerative disorder; patient presentation may be sporadic or due to an inherited familial condition. All patients have mutations in their mitochondrial DNA; approximately $80 \%$ of patients show an A to $G$ transition at position 3243 of their transfer RNA-leu gene. $^{37}$

\section{Pathogenesis}

Multisystemic involvement is observed in MELAS but the pathogenesis of symptoms is not completely clear. Mitochondrial angiopathies of vessels are reported but it is also suggested that the stroke-like episodes occurring in MELAS patients may actually be non-vascular and instead related to mitochondrial dysfunction in the brain parenchyma, leading to tissue ischaemia. Increased free radical formation due to dysfunctional oxidative phosphorylation is also a risk factor. $^{38}$

\section{Clinical manifestations}

Distribution of normal and mutant mitochondrial DNA is highly variable causing a wide array of phenotypes. Characteristic features include mitochondrial encephalopathy characterised by seizures, lactic acidosis, stroke-like episodes, migrainous headaches and other features of mitochondrial illnesses.

\section{Diagnosis and management}

Diagnosis is dependent on clinical presentation, biochemical assessment, muscle biopsy and imaging studies. T2-weighted MRI shows multifocal areas of hyperintense signal confined to the cortex of the cerebrum, cerebellum, and adjacent white matter; deep white matter is relatively spared allowing differentiation from normal cerebrovascular disease. The lesions typically affect the occipito-parietal regions and rarely affect normal vascular territories, supporting an alternative mechanism to pure ischaemic infarction. ${ }^{39}$ As well as counselling and support, patients may require vitamins and dietary supplements. Koga and colleagues have suggested that Larginine improves the symptoms of stroke-like episodes in MELAS. $^{40}$

\section{Marfan syndrome \\ Genetic basis}

Marfan syndrome is a multisystem disorder of connective tissue caused by mutations in the extracellular matrix protein fibrillin 1; linkage analysis mapped the fibrillin gene locus to chromosome 15q21.1. It is inherited as an autosomal dominant disorder although most families have unique or private mutations. $^{41}$

\section{Pathogenesis}

Fibrillin $\mathrm{l}$ is an extracellular matrix protein expressed in many tissues including the heart and elastic arteries. In its mutated form connections between elastic fibres and vascular smooth muscle cells are defective and the cells adopt an abnormal synthetic repertoire. This leads to elastic fibre calcification, vascular wall inflammation, intimal hyperplasia and structural collapse of the vessel wall. ${ }^{41}$

\section{Clinical manifestations}

Manifestations typically involve the cardiovascular, skeletal and ocular systems. Cardiac abnormalities include mitral and aortic incompetence and aortic dissection, with other features including tall stature, joint hypermobility and ectopia lentis. ${ }^{41}$ Neurovascular complications are relatively rare. In 2002 Wityk and colleagues conducted a large retrospective study of Marfan syndrome patients and reported that over an 8 year period only $3.5 \%$ of patients suffered a neurovascular event; approximately $65 \%$ of these were TIAs, $10 \%$ cerebral infarctions, $10 \%$ spinal cord infarctions, $10 \%$ subdural haematomas and 5\% spinal subarachnoid haemorrhage ( $\mathrm{SAH})$. Of those suffering with cerebral ischaemia a cardioembolic source was identified in 12 out of 13 patients. Chronic anticoagulant treatment was a likely cause in two of three patients with haemorrhagic events. ${ }^{42}$

\section{Diagnosis and management}

Diagnosis requires a multidisciplinary approach (geneticist, cardiologist, ophthalmologist). No specific treatment currently exists for Marfan syndrome and management focuses on counselling and support and symptomatic control. Regular review of aortic growth is essential to assess the risk of arterial dissection.

\section{Ehlers-Danlos syndrome type IV; the vascular type Genetic basis}

Ehlers-Danlos syndrome type IV is an autosomal dominant condition resulting from mutations in the gene for type III procollagen (COL3Al on chromosome 2q31); the mutational spectrum is broad with novel mutations being a common occurrence. $^{43}$ 


\section{Pathogenesis}

Patients become symptomatic because the mutant collagen formed has reduced inherent strength, elasticity, integrity, and healing properties. Its integration into normal connective tissue matrices is defective.

\section{Clinical manifestations}

Classical symptoms are a characteristic facial appearance, thin and translucent skin that bruises easily, and fragile arteries and intestines that are prone to rupture. Neurovascular complications occur in approximately $10 \%$ of patients and include intracerebral aneurysms and carotid and vertebral arterial dissection. $^{43}$

\section{Diagnosis and management}

Diagnosis is dependent on clinical examination, biochemical examination of cultured skin fibroblasts and molecular testing of DNA. No specific treatment currently exists for EhlersDanlos syndrome and management focuses on counselling and support and symptomatic control. Patients have a reduced life expectancy with death commonly as a consequence of thoracic or abdominal aorta rupture. ${ }^{43}$

\section{Miscellaneous}

Ischaemic stroke is also a recognised complication of pseudoxanthoma elasticum (mutations on the ATP binding ABCC6 gene on chromosome $16 \mathrm{pl3}$ leading to chronic calcium deposition in arteries), ${ }^{44}$ neurofibromatosis type 1 (NFl) (predisposition to moya-moya-like phenomenon leading to both ischaemic and haemorrhagic stroke), and other conditions including heritable cardiomyopathies, dysrhythmias, vasculopathies, coagulopathies, dyslipidaemias and haemoglobinopathies, although in many of these the association with stroke is controversial. ${ }^{10}$

\section{POLYGENIC DISORDERS AND STROKE}

The majority of cases of stroke present as multifactorial disorders or complex traits for which recognised patterns of inheritance cannot be demonstrated. However, twin and family-based studies have demonstrated that numerous genetic factors do influence the risk of stroke in these patients. As with other complex traits, the genetic aetiology of common stroke is likely to be polygenic. It is likely that there are many alleles which have minimal effects individually, but with their wide distribution throughout the population, the summative impact on stroke is large. Candidate gene and case-control studies are classically used to investigate these genetic predispositions. However, for accurate detection of these small relative risk genes, huge sample sizes are necessary. ${ }^{45}$ This, together with varying study design, is a definite cause for the inconsistent conclusions drawn by different studies.

\section{A PRACTICAL APPROACH TO MANAGING YOUNG STROKE PATIENTS}

Single gene disorders causing stroke generally present at a younger age $(<40$ years), either with stroke or with other clinical features related to the disorder. However, when presented with a young individual who has suffered a stroke, other more common aetiologies must also be considered. Of particular note are heart disease (including congenital heart disease, rheumatic valve disease, mitral valve prolapse, endocarditis, arrhythmias and previous cardiac surgery), vasculitis (including systemic lupus erythematosus, rheumatoid arthritis, Sjögren syndrome, polyarteritis nodosa, sarcoidosis and inflammatory bowel disease) and hypercoagulable states (including antiphospholipid syndrome and antithrombin III/protein C/ protein $\mathrm{S}$ deficiencies). Other causes to consider include substance abuse (cocaine, heroin), trauma, arterial dissections, venous thrombosis and migraine. ${ }^{46}$

Initial management should include a detailed history and examination directed towards both common and rare aetiologies; the physical examination should include thorough neurological, cardiovascular, and ophthalmological assessment. Initial investigations must include blood tests (full blood count, prothrombin time, activated partial thromboplastin time, biochemistry and electrolytes, glucose, erythrocyte sedimentation rate) and a computed tomographic scan of the head. If there is a personal or family history of thrombosis a more detailed coagulation profile should be requested. Further tests to consider include a pregnancy test, chest $x$ ray, electrocardiogram, echocardiogram and extracranial (carotid-vertebral) Doppler ultrasound. Conventional angiography of cerebral and neck vessels should be considered if dissection is suspected. Furthermore, toxicology studies (even when no drug use is acknowledged), autoantibody screens, electrophoresis studies and cerebrospinal fluid analysis may prove helpful. ${ }^{46}$

\section{CONCLUSIONS AND FUTURE DIRECTIONS}

Stroke is a major cause of death and disability throughout the world. Progress continues to be made into the identification and understanding of single gene disorders associated with stroke, but comparatively little is known about the genetic factors influencing polygenic and multifactorial stroke. It is important that, in view of the complex heterogeneity of stroke, research is targeted at individual stroke subtypes because genetic influences undoubtedly affect different forms of stroke in different ways. Large sample sizes remain the key to success. A collaborative multicentre investigation may be the route to elucidating successfully the genetic basis of polygenic and multifactorial stroke. Ultimately the goal must be to understand fully what factors influence stroke outcome and thus introduce new treatment options for when preventative measures fail.

\section{Authors' affiliations}

John Francis, Pradeep Khanna, Senthil Raghunathan, Nevill Hall Hospital, Abergavenny, UK

Competing interests: None.

\section{REFERENCES}

1 World Health Organization. The WHO STEPwise approach to stroke surveillance. Geneva: WHO, 2005.

2 Adams HP, Bendixen BH, Kappelle $\amalg$, et al. Classification of subtype of acute ischaemic stroke: definitions for use in a multicenter clinical trial. TOAST (Trial of Org 10172 in Acute Stroke Treatment). Stroke 1993;24:35-41.

3 Philip M, Bath W, Lees KR. ABC of arterial and venous disease. BMJ 2000;320:920-3.

4 Sacco RL, Ellenberg JH, Mohr JP, et al. Infarcts of undetermined cause: the NINCDS Stroke Data Bank. Ann Neurology 1989;25:382-90.

5 Jousilahti P, Rastenyte D, Tuomilehto J, et al. Parental history of cardiovascular disease and risk of stroke. A prospective follow-up of 14371 middle-aged men and women in Finland. Stroke 1997;28:1361-6.

6 Bak S, Gaist D, Sindrup SH, et al. Genetic liability in stroke: a long-term followup study of Danish twins. Stroke 2002;33:769-74.

7 Floßmann E, Schulz UGR, Rothwell PM. Systematic review of methods and results of studies of the genetic epidemiology of ischaemic stroke. Stroke 2004;35:212-27.

8 Razvi SSM, Bone I. Single gene disorders causing ischaemic stroke. J Neurol 2006;253:685-700.

9 Natowicz M, Kelley RI. Mendelian etiologies of stroke. Ann Neurol 1987;22:175-92.

10 Dichgans M. Genetics of ischaemic stroke. Lancet Neurol 2007;6:149-61.

11 Peters N, Opherk C, Bergmann T, et al. Spectrum of mutations in biopsy-proven CADASIL: implications for diagnostic strategies. Arch Neurol 2005;62:1091-4.

12 Joutel A, Vahedi K, Corpechot C, et al. Strong clustering and stereotyped nature of Notch 3 mutations in CADASIL patients. Lancet 1997;350:1511-15.

13 Peters N, Opherk C, Zacherle S, et al. CADASIL associated Notch3 mutations have differential effects on ligand binding and ligand-induced Notch3 receptor signalling through RBK-Jk. Exp Cell Res 2004;299:454-64. 
14 Joutel A, Andreux F, Gaulis S, et al. The ectodomain of Notch3 receptor accumulates within the cerebrovasculature of CADASIL patients. J Clin Invest 2000;105:597-605.

15 Dichgans $M$, Mayer $M$, Uttner I, et al. The phenotypic spectrum of CADASIL: clinical findings in 102 cases. Ann Neurol 1998;44:731-9.

16 Rouchoux MM, Chabriat $\mathrm{H}$, Bousser MG et al. Presence of ultrastructural arterial lesions in muscle and skin vessels of patients with CADASIL. Stroke 1994;25:2291-2

17 Lechner-Scott J, Engelter S, Steck A, et al. A patient with CADASIL confirmed by sural nerve biopsy. J Neurol Neurosurg Psychiatry 1994;60:235-6.

18 Rouchoux MM, Guerouaou D, Vandenhaute B, et al. Systemic vascular smooth muscle impairment in CADASIL. Acta Neuropathology (Berl) 1995;89:500-12.

19 O'Sullivan M, Jarosz JM, Martin RJ, et al. MRI hyperintensities of the temporal lobe and external capsule in patients with CADASIL. Neurology 2001;56:628-34

20 Arima K, Yanagawa S, Ito N, et al. Cerebral arterial pathology of CADASIL and CARASIL (Maeda syndrome). Neuropathology 2003;23:327-34.

21 Opherk C, Peters N, Herzog J, et al. Long-term prognosis and causes of death in CADASIL: a retrospective study in 411 patients. Brain 2004;127:2533-9.

22 Fukutake T, Hirayama K. Familial young-adult-onset arteriosclerotic leucoencephalopathy with alopecia and lumbago without arterial hypertension. Eur Neurology 1995;35:69-79.

23 Fukutake T. Young-adult-onset hereditary subcortical vascular dementia: cerebral autosomal recessive arteriosclerosis with subcortical infarcts and leucoencephalopathy (CARASIL). Rinsho Shinkeigaku 1999;39:50-2.

24 Mineharu Y, Takenaka K, Yamakawa H, et al. Inheritance pattern of familial moyamoya disease: autosomal dominant mode and genomic imprinting. J Neurol Neurosurg Psychiatry 2006;77:1025-9.

25 Ikezaki K, Han DH, Kawano T, et al. A clinical comparison of definite moyamoya disease between South Korea and Japan. Stroke 1997;28:2513-2517.

26 MacDermot KD, Holmes A, Miners AH. Anderson-Fabry disease: clinical manifestations and impact of disease in a cohort of 98 hemizygous males. J Med Genetics 2001;38:750-60.

27 Grewal RP. Stroke in Fabry's disease. J Neurol 1994;241:153-6.

28 Moore DF, Altarescu G, Herscovitch P, et al. Enzyme replacement reverses abnormal cerebrovascular responses in Fabry disease. BMC Neurology 2002;2:4.

29 Switzer JA, Hess DC, Nichols FT, et al. Pathophysiology and treatment of stroke in sickle-cell disease: present and future. Lancet Neurol 2006;5:501-12.
30 Ohene-Frempong K, Weiner SJ, Sleeper LA, et al. Cerebrovascular accidents in sickle cell disease: rates and risk factors. Blood 1998;91:288-94.

31 Adams RJ, McKie VC, Hsu L, et al. Prevention of first stroke by transfusions in children with sickle cell anaemia and abnormal results on transcranial Doppler ultrasonography. N Engl J Med 1998;339:5-11.

32 Gulbis B, Haberman D, Dufour D, et al. Hydroxyurea for sickle cell disease in children and for prevention of cerebrovascular events: the Belgian experience. Blood 2005; 105:2685-90

33 Mudd SH, Shovby F, Levy HL, et al. The natural history of homocystinuria due to cystathione beta-synthase deficiency. Am J Hum Genet 1985;37:1-31

34 Kraus JP, Janosik M, Kozich V, et al. Cystathione beta-synthase mutations in homocystinuria. Hum Mutations 1999;13:362-75.

35 Hassan A, Hunt BJ, O'Sullivan M, et al. Homocysteine is a risk factor for cerebral small vessel disease, acting via endothelial dysfunction. Brain 2004;127:212-9.

36 Yap S, Boers GH, Wilcken B, et al. Vascular outcome of patients with homocystinuria due to cystathione-beta synthase deficiency treated chronically; a multicenter observational study. Arterioscler Thromb Vasc Biol 2001;21:2080-5.

37 Enter C, Muller-Hocker J, Kurlemann G et al. A specific point mutation in the mitochondrial genome of Caucasians with MELAS. Hum Genet $1991 ; 88: 233-6$

38 Scaglia F. MELAS syndrome. Emedicine publication (Accessed 25 March 2007).

39 Matthews PM, Tampieri D, Berkovic SF, et al. Magnetic resonance imaging shows specific abnormalities in the MELAS syndrome. Neurology $1991 ; 41: 1043-6$

40 Koga Y, Akita Y, Nishioka J, et al. L-arginine improves the symptoms of strokelike episodes in MELAS. Neurology 2005;64:710-2.

41 Judge DP, Dietz HC. Marfan's syndrome. Lancet 2005;366:1965-76.

42 Wityk RJ, Zanferrari C, Oppenheimer S. Neurovascular complications of Marfan syndrome: a retrospective, hospital-based study. Stroke 2002;33:680-4.

43 Pepin M, Schwarze U, Superti-Furga A, et al. Clinical and genetic features of Ehlers-Danlos syndrome type IV, the vascular type. $N$ Engl J Med 2000;342:673-80

44 van den Berg JS, Hennekam RC, Cruysberg JR, et al. Prevalence of symptomatic intracranial aneurysm and ischaemic stroke in pseudoxanthoma elasticum. Cerebrovasc Dis 2000;10:315-9.

45 Healey DG. Case-control studies in the genomic era: a clinician's guide. Lancet Neurol 2006:5:701-7.

46 Marcoux M. Stroke in young adults. CNI Review 2000;11:Article 2.

\section{Take advantage of BMJ Journals' remarkable catalogue of titles with Related Collections}

No busy professional has time to browse through all pertinent journals to find relevant articles, but with Related Collections you no longer have to. Follow the "Related Collections" link from any article and use the "Show Collections from other Journals" to expand your search across all BMJ Journals. Or simply follow the "Browse by topic" link on the home page. By setting up your own collections and receiving email alerts every time an article is added to your chosen area, you can build up your own significant body of knowledge. 